\title{
GRAVITY MIXERS WITH VIBRATION ACTIVATOR IN CONSTRUCTION ENGINEERING
}

\author{
Victor Kuzmichev ${ }^{1}$, Vladimir Verstov ${ }^{2}$ \\ ${ }^{1}$ Peter the Great Saint Petersburg Polytechnic University, \\ Polytechnicheskaya st. 29, St. Petersburg, Russia \\ ${ }^{2}$ Saint Petersburg State University of Architecture and Civil Engineering \\ Vtoraja Krasnoarmejskaja ul. 4, St. Petersburg, Russia \\ ${ }^{1}$ kuzmichev_va@mail.ru, ${ }^{2}$ 5750195@mail.ru
}

\begin{abstract}
Vibration processes and corresponding machinery and equipment are widely used in construction, production of construction materials and other industries. Compaction, crushing, separation, piling, dosing and transportation of bulk materials are just several processes where it is expedient to use vibration.

The article presents original designs of gravity (drum) mixers with vibration activators placed inside the mixing chamber. A vibration activator is installed in "dead" zones located along the geometrical axis of the mixing chamber where intensity of convective mixing is low.

Methods of design of balanced eccentric vibration activators of precessing type are considered. Results of production tests with regard to the industrial design of the gravity vibration mixer are presented. Considerable attention is paid to measurement of the vibration level reflecting the quality of dynamic balancing of the vibration activator. Vibrational impact on the environment and maintenance personnel amounts to $\sim 5 \mathrm{~m} / \mathrm{s}^{2}$, corresponding to standard values for processing equipment as per GOST 22061-76.
\end{abstract}

\section{Keywords \\ Gravity mixer, vibration activator, design methods, dynamic balancing.}

\section{Introduction}

The history of mankind is inextricably associated with inventions, discoveries, development and improvement of various technical facilities and engineering processes. At present, their diversity even within the framework of the same industry has reached the level when further improvement of technical facilities and engineering processes is impossible without modern methods for searching innovative technologies.

It is obvious that it is worthwhile to consider the social and economic expediency of the development and application of new-generation machinery and equipment only given the necessary scientific and technical potential ensuring the fundamental possibility of their design, manufacturing and practical use. At the same time, the social and economic expediency indicates that, firstly, their manufacturing and practical use to meet particular needs is economically possible and advantageous, and that, secondly, anthropogenic criteria of progressive development do not deteriorate.
Important principles of the laws of historical technology development are the following:

- the principle of limit transition: technical systems (TS) with constant functions stabilize and cease further constructive evolution, if their technical solution is approaching the global extremum based on the principle of operation (PO) and design, unless new physical effects, providing improved $\mathrm{PO}$, arise;

- the principle of preference: when moving to new PO in TS using particular physical effects, preference is given to newer principles, which were discovered later.

In 1930s, H. Freundlich discovered the effect of thixotropy, i.e. viscosity reduction in disperse systems under mechanical impacts, followed by restoration of the structure after impact elimination. Vibration holds a prominent place among various mechanical impacts.

Mixing of materials is a mechanical process resulting in uniform distribution of mineral constituents' particles and a binder in a mixed volume, which, in their turn, form a uniform mix. 
Based on the developed ideas, the following types of mixing are distinguished: convective and diffusing. Convective mixing is classified as a macromixing process while diffusive mixing is classified as a micromixing process.

Along with mixing, separation takes place in a mixer (separation of constituents' particles and their concentration in certain areas of the mixer body under the action of gravitational and centrifugal forces). Actual mix formation usually represents superposition of mixing and separation.

Upon mixing in mixers of various types, the mix structure changes continuously and, therefore, its structural and rheological properties change. Control over structural and rheological properties is the main direction of intensification of the diffusion component with regard to mixing processes. At the present time, the following methods are used: pseudo-liquefaction, use of surface active agents (SAA) ensuring mix viscosity reduction; binder feeding by means of nozzles, etc.

Vibration is one of the widely applied types of mechanical impact on environments in the field of construction and production of construction materials, considerably affecting changes in rheological properties of mixes (Bauman, Bykhovsky, 1977; Blekhman, 1994; Verstov et al., 20013; Chelomey, 1981; Efremov, Lobanov, 2008, 2009).

Gravity mixers have a number of advantages in comparison with mixers of forced action: gravity mixers have simple design and low energy intensity. Their disadvan- tage is in low intensity of the mixing process. Such mixers are mainly used in flow concrete mixing.

To intensify the mixing process, it is reasonable to apply vibration.

\section{Description of designs}

The accumulated experience in the design of various vibration mixers presented in the literature (Kuzmichev, 2013,2014 ) made it possible to develop production drawings and manufacture a gravity vibration mixer with the prepared batch volume of $0.5 \mathrm{~m}^{3}$ by improvement of the commercial model SB-91B at the Tyumen Construction Machinery Plant.

The improvement implied installation of a balanced precessing eccentric vibration activator of the cone shape along the geometrical axis of the drum. A fragment of the production drawing and photos are shown in Figures 1 and 2.

The mixing process is as follows. When the motor is turned on, the drum and the vibration exciter start performing working motions. Under the influence of vibration, the mix is diluted and mixed with blades in the rotating drum.

In order to confirm that an integrated vibration activator enhances the capabilities of the mixer regarding the mix composition, analysis of the mixing process was carried out.

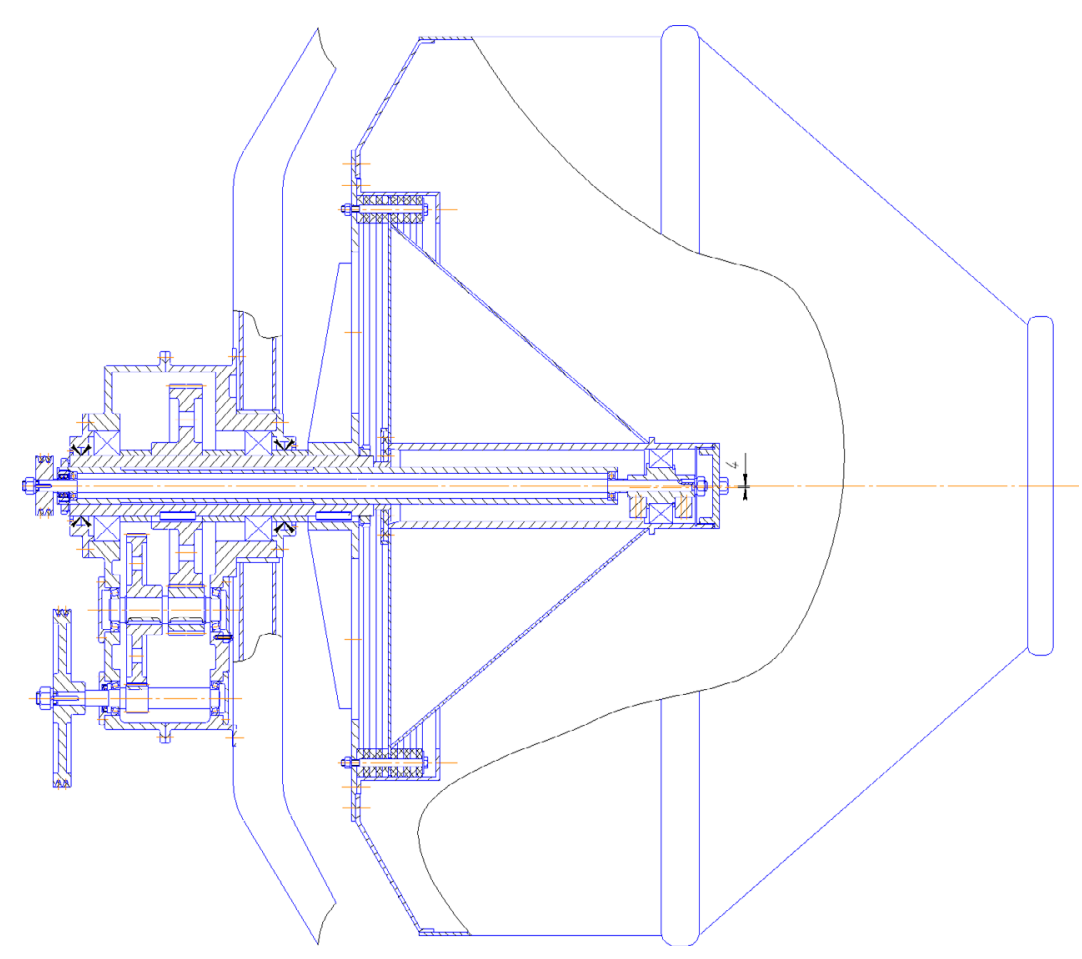

Figure 1. Fragment of the production drawing 

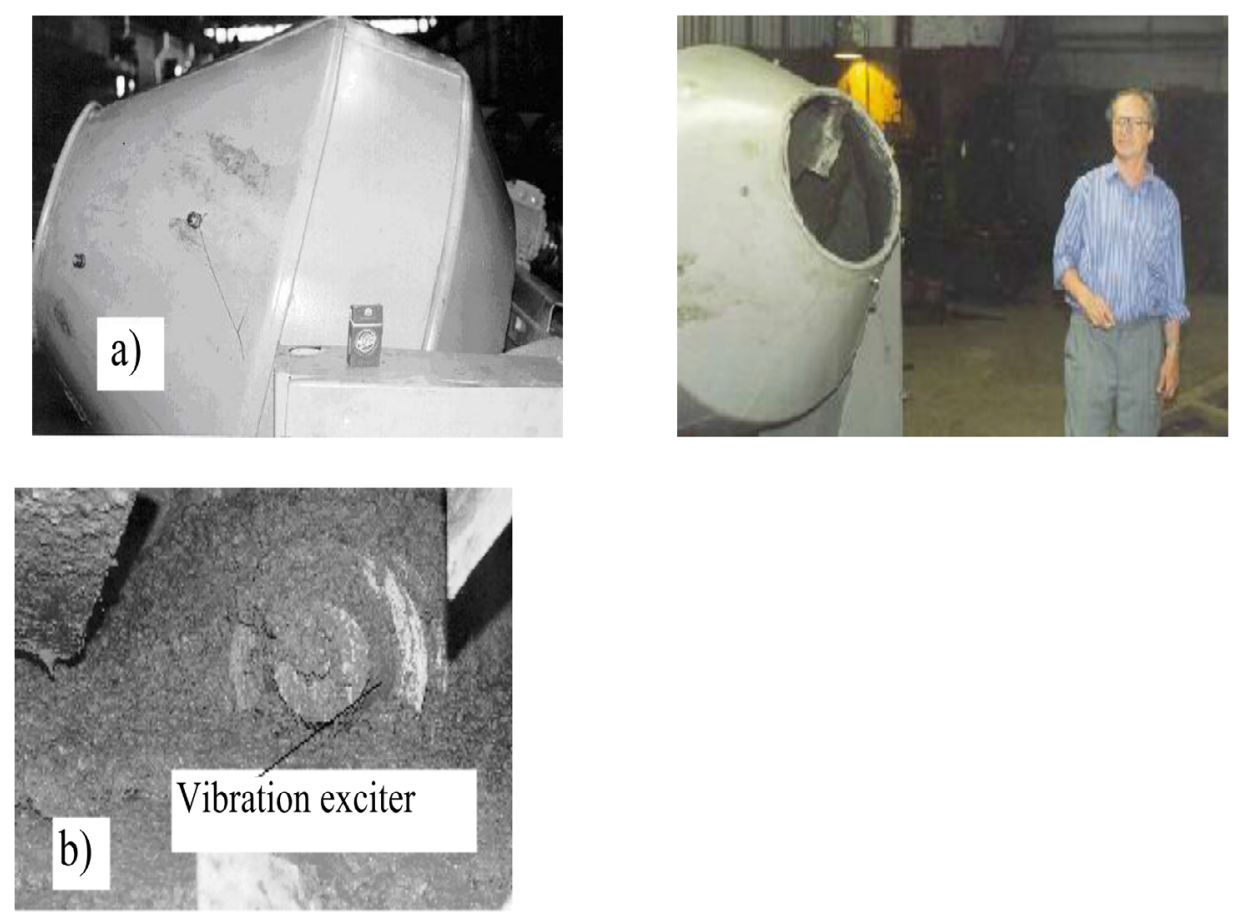

Figure 2. Gravity vibration mixer:

a) fragment showing the vibration level at the mixer frame during mixing; b) fragment of the mixing process

The following concrete grades were selected as test objects: $\mathrm{M} 300$, a mix with the cone slump of $0 \mathrm{~cm}$ and the stiffness index of $10 \mathrm{~s} ; \mathrm{M} 200$, a mix with the cone slump of $0 \mathrm{~cm}$ and the stiffness index of $30 \mathrm{~s}$.

Table 1. Technical characteristics of vibration mixers

\begin{tabular}{|l|c|}
\hline Prepared batch volume, $\mathrm{m}^{3}$ & 0.5 \\
\hline $\begin{array}{l}\text { Rotation frequency of the mixing } \\
\text { drum, rad/s }\end{array}$ & 2.0 \\
\hline Parameters of the vibration exciter: & 3.5 \\
- oscillation amplitude, $\mathrm{mm} ;$ & 220 \\
- oscillation frequency, rad/s; & \\
- maximum acceleration of oscilla- & 170 \\
tions, $\mathrm{m} / \mathrm{s}^{2} ;$ & 0.2 \\
- vibrating surface, $\mathrm{m}^{2} ;$ & precessing \\
- type of oscillations & \\
\hline Installed power of the drive: & 4.0 \\
- for rotation of the drum and vibration & 1.1 \\
exciter, $\mathrm{kW}$ & $1,850 \times 2,000 \times 1,800$ \\
- for drum tilting, $\mathrm{kW}$ & $1,850 \times 2,000 \times 1,800$ \\
\hline Dimensions, mm & 1,100 \\
\hline
\end{tabular}

Compositions of concrete mixes were accepted in accordance with the standards of material consumption established at the Tyumen Reinforced Concrete Products Plant. The obtained control samples were tested in accordance with GOST 10180-90. After 28 days of hard- ening, the strength of the samples corresponded to the standards, the coefficient of strength uniformity (coefficient of variation) was $10 \%$; the mixing time was $90 \mathrm{~s}$.

\section{Technique of balancing of vibration activators}

A console precessing three-point vibration exciter is shown in Figure 3. It consists of carrying drive shaft 1 , main bearings 2 , a body designed to extend the active vibration surface by connecting pipe 3 and cone shell 7 , rod bearing 4 installed on the eccentric bushing with mechanically set eccentricity $e$, counterbalances 5 , and coupling 6 located concentrically in relation to the carrying drive shaft.

Upon rotation of the carrying drive shaft, the vibration activator body executes a precessing motion with the shaft rotation frequency and nutation angle:

$$
\beta=\frac{\operatorname{arctg} e}{L}
$$

Design models are presented in Figure 3.

In accordance with the calculation procedure described in detail in (Kuzmichev, 2013, 2014, 2017), upon application of the superposition method (the principle of independence of forces), the resultant of centrifugal forces $Q$ and its application point (distance $L$ ) are determined taking into account the following equations:

1. for the cylindrical part (Figure 3a): 


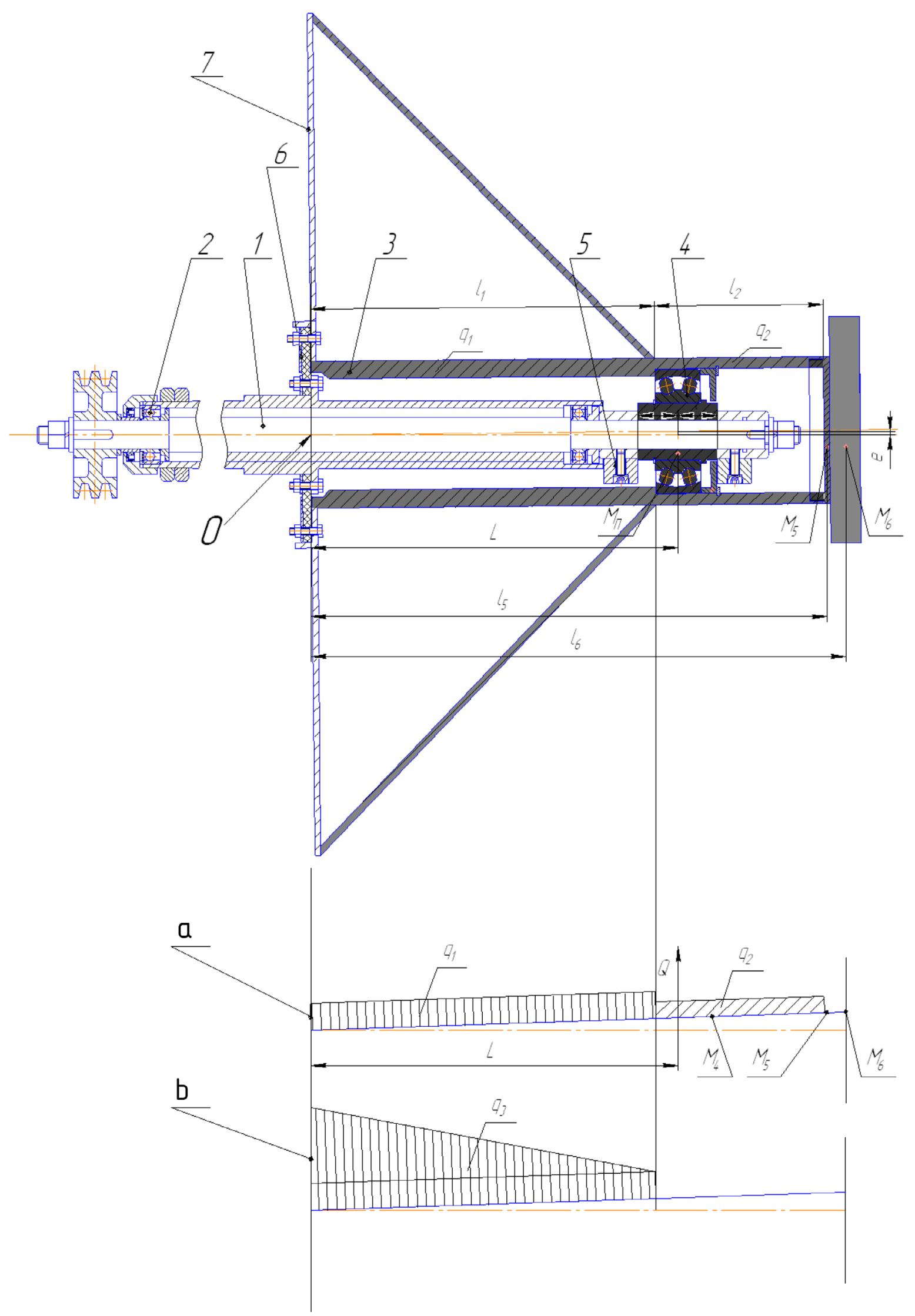

Figure 3. Design model of the assembled vibration activator 


\section{Architecture and Engineering Volume 2 Issue 4}

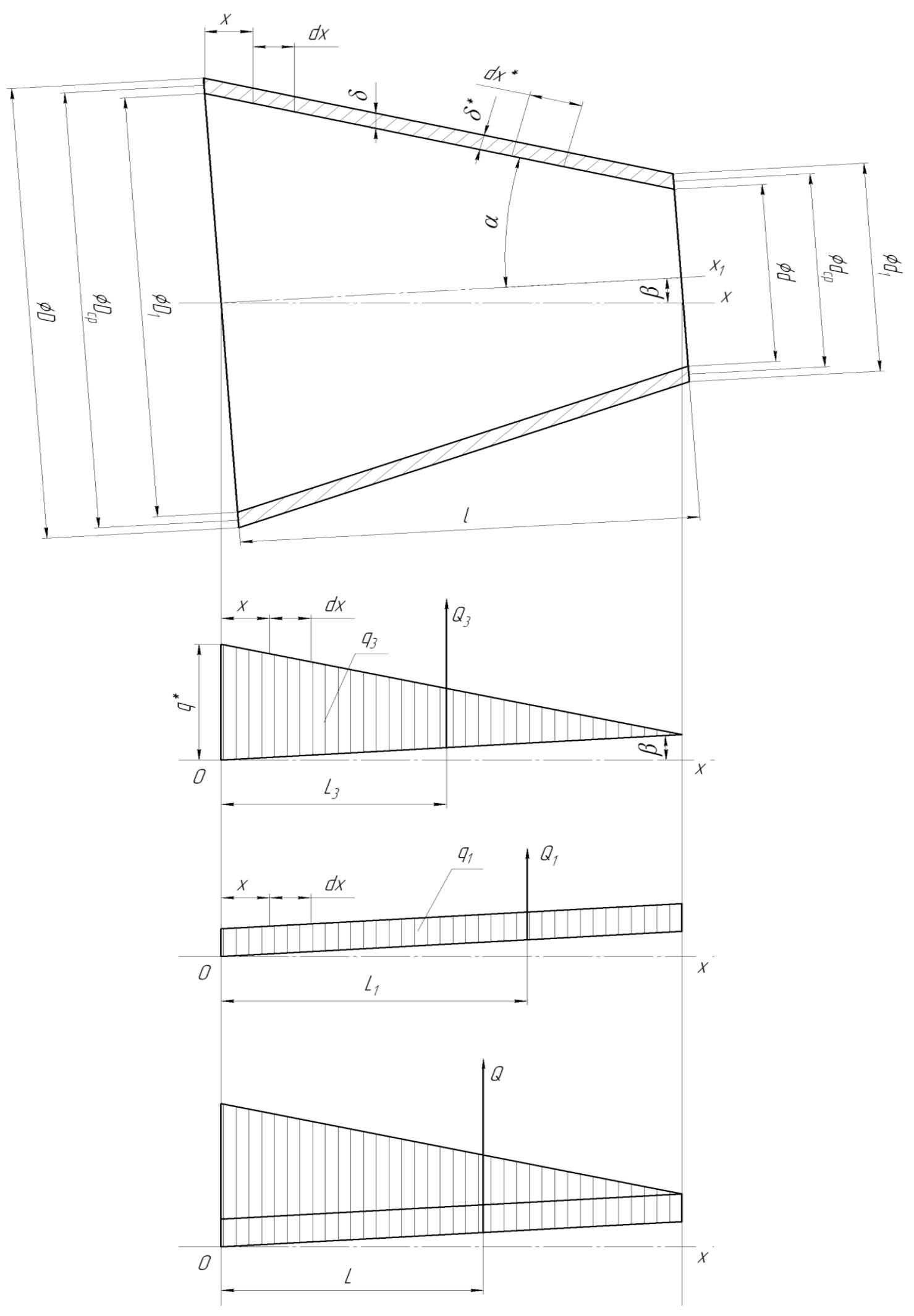

Figure 4. Design model of the cone shell 


$$
\begin{aligned}
& \sum Q=Q_{1}+Q_{2}+Q_{5}+Q_{6}= \\
& =\omega^{2} \operatorname{tg} \beta\left(\frac{1}{2} q_{1} l_{1}^{2}+\frac{1}{2} q_{2}\left[\left(l_{1}+l_{2}\right)^{2}-l_{1}^{2}\right]+\right. \\
& \left.+M_{5} l_{5}+M_{6} l_{6}\right) \\
& L=\frac{Q_{1} l_{1}+Q_{2} l_{2}+Q_{5} l_{5}+Q_{6} l_{6}}{\sum Q}= \\
& =\frac{\omega^{2} \operatorname{tg} \beta\left(\frac{1}{3} q_{1} l_{1}^{3}+\frac{1}{3} q_{2}\left[\left(l_{1}+l_{2}\right)^{3}-l_{1}^{3}\right]+M_{5} l_{5}^{2}+M_{6} l_{6}^{2}\right)}{\sum Q}
\end{aligned}
$$

Let us consider the procedure for the development of the cone shell design model in more detail (Figure 4).

The design wall thickness is determined based on the condition of equality of the mass per unit length:

$$
\begin{aligned}
& d x \cdot \delta \cdot \rho=d x^{*} \\
& \delta=\frac{d x^{*} \cdot \delta^{*}}{d x^{*} \cdot \cos \alpha} \\
& \delta=\frac{\delta^{*}}{\cos \alpha}
\end{aligned}
$$

Here $\delta$ is the sheet thickness.

$q_{1}=\pi d_{\text {ave }} \delta \rho$

$Q_{1}^{1}=\frac{1}{2} \omega^{2} q_{1} l^{2} \operatorname{tg} \beta ; L_{1}^{1}=\frac{2}{3} l$.

$q_{3}=q^{*}\left(1-\frac{x}{l}\right)$

$Q_{3}^{1}=\frac{1}{6} \omega^{2} q^{*} l^{2} \operatorname{tg} \beta$

$q^{*}=\pi\left(D_{a v e}-d_{\text {ave }}\right) \delta$

$L_{3}^{1}=\frac{l}{2}$

$\sum Q^{1}=Q_{1}^{1}+Q_{3}^{1}=\omega^{2} \operatorname{tg} \beta\left(\frac{1}{2} q_{1} l^{2}+\frac{1}{6} q \cdot l^{2}\right)$

$L^{1}=\frac{Q_{1}^{1} L_{1}^{1}+Q_{3}^{1} L_{3}^{1}}{\sum Q^{1}}=\frac{\omega^{2} \operatorname{tg} \beta}{\sum Q^{1}}\left(\frac{1}{3} q_{1} l_{1}^{3}+\frac{1}{12} q_{3}^{*} l_{3}^{3}\right)$.
(Note: in Figure $4 \quad L_{1} \rightarrow L_{1}^{1} ; L_{3} \rightarrow L_{3}^{1} \quad$ ).

The total centrifugal force and its application point are determined based on the following equations:

$$
\sum Q^{* *}=\sum Q+\sum Q^{1} ; \sum L^{* *}=\frac{L \sum Q+L^{1} \sum Q^{1}}{\sum Q^{* *}}
$$

The rod bearing assembly is designed and its mass $m_{\text {bear }}$ and center-of-gravity position are determined. The vibration exciter construction is made with one rod bearing center-of-gravity of which is determined at the point of application of the resultant of centrifugal forces.

The mass of the bearing assembly includes the bearing, eccentric part of the bushing and cover. The centrifugal force from the mass of the rod bearing assembly is determined according to the following equation:

$R=m_{\text {bear }} \cdot e \cdot \omega^{2}$

Dynamic balancing is carried out in accordance with the design model presented in Figure 5.

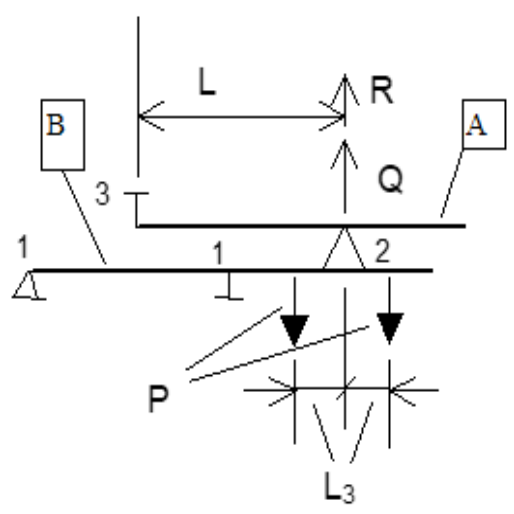

Figure 5. Design model

Balancing condition:

$P=1 / 2\left(\sum Q^{* *}+R\right)$

(here $\left.\sum Q^{* *}=Q ; \sum L^{* *}=L\right)$

The counterbalances are located symmetrically and designed in accordance with (Kuzmichev, 2013, 2014, 2017).

Vibration monitoring on a mixer reflecting the quality of dynamic balancing was performed using the following devices: noise and vibration meter VShV-003-M2 (BШB-003-M2), logarithmic noise-and-vibration integrator ShVIL-01 (ШВИЛ-01), air humidity and temperature meter Testo-15. Sensors were mounted on the traverse. Measurements were carried out in three modes: test No. 1 (the 


\section{Architecture and Engineering Volume 2 Issue 4}

Table 1. Vibration level on the mixer body

\begin{tabular}{|c|c|c|c|c|c|c|}
\hline $\begin{array}{c}\text { Measurement } \\
\text { mode }\end{array}$ & $\begin{array}{c}\text { Acceleration of } \\
\text { vibration exciter } \\
\text { oscillations V, } \\
\mathrm{m} / \mathrm{s}^{2}\end{array}$ & $\begin{array}{c}\text { Acceleration } \\
\text { along } X, \\
\mathrm{~m} / \mathrm{s}^{2}\end{array}$ & $\begin{array}{c}\text { Acceleration } \\
\text { along } Y, \\
\mathrm{~m} / \mathrm{s}^{2}\end{array}$ & $\begin{array}{c}\text { Acceleration } \\
\text { along } Z, \\
\mathrm{~m} / \mathrm{s}^{2}\end{array}$ & $\begin{array}{c}\text { Ro o }-\mathrm{m} \text { e a } \mathrm{n}- \\
\text { square } \\
\text { value } \\
\frac{\sqrt{x^{2}+y^{2}+z^{2}}}{\mathrm{~m} / \mathrm{s}^{2}}\end{array}$ & $\begin{array}{c}\frac{V}{U} \\
U\end{array}$ \\
\hline 1 & 170 & 2.1 & 2.8 & 2.5 & 4.3 & 40 \\
\hline 2 & 170 & 2.8 & 3.4 & 3.2 & 5.45 & 31 \\
\hline
\end{tabular}

vibrator is turned on, the drum does not rotate); test No. 2 (both drives (for vibration and rotation of the drum (mixing process)) are turned on). The results of vibration acceleration measurements are presented in Table 2.

The analysis of the measurement results shows that application of balanced eccentric vibration activators ensures reduction of vibration affecting the environment (drive, frame, etc.) by $\sim 30$ times. The measured peak values of acceleration amount to $\sim 5 \mathrm{~m} / \mathrm{s}^{2}$, corresponding to standard values for processing equipment as per GOST 22061-76.

\section{Conclusions}

The presented materials confirm legitimacy of the balancing technique for vibration activators which is presented in detail in (Kuzmichev and Verstov, 2017a, 2017b), and expediency of their application in mixing equipment for production of construction mixes.
It should be noted that numerous researches in the field of intensification of technological processes with vibration application, conducted by Russian researchers, have shown that the main principles of physical and chemical mechanics of disperse systems can also be successfully used in mixing.

Control over structural and rheological properties of mixes at the stage of mixing, in particular, destruction of the structure of mixed materials and, therefore, viscosity reduction, allows increasing uniformity of mixed materials, production quality, affecting molding processes, etc.

It is expedient to use gravity mixers with vibration activators for mixing of plastic and dry concrete mixes, as well as other highly concentrated disperse systems, e.g. dry mixes, powders, etc. 


\section{References}

Bauman, V.A., Bykhovsky, I.I. (1977). Vibratcionnye mashiny i protcessy $v$ stroitelstve [Vibration machines and processes in construction]. Moscow: Vysshaya Shkola, p.256. (in Russian)

Blekhman, I.I. (1994). Vibratcionnaia mekhanika [Vibration mechanics]. Moscow: Fizmatlit, p.400. (in Russian)

Chelomey, V.N. (1981). Vibratsiya $v$ tekhnike. Spravochnik v 6 tomakh [Machinery vibrations. Reference book in 6 volumes]. Moscow: Mashinostroenie Publishing House, vol.6, p.509. (in Russian)

Efremov, I.M., Lobanov, D.V. (2008). Novye rotornye smesiteli s razlichnymi sistemami vibrovozbuzhdeniya [New rotary mixing devices with various systems of vibration activation]. Stroitel'nye i dorozhnye mashiny [Construction and road machinery], 9, pp. 7-9. (in Russian)

Efremov, I.M., Lobanov, D.V. (2009). Vibrobetonosmesiteli: put' dlinoy v 70 let [Vibration concrete finishers: 70 years old experience]. Stroitel'nye i dorozhnye mashiny [Construction and road machinery], 10, pp. 15-19. (in Russian)

Kuzmichev, V.A. (2013). Osnovy proektirovaniya vibromikserov [Basics of designing of vibration mixers]. LAP LAMBERT AcademicPublishing, p.136. (in Russian)

Kuzmichev, V. A. (2014). Osnovy proektirovaniia vibratcionnogo oborudovaniia [Fundamentals of vibration equipment design]. Saint Petersburg: Lan, p.208. (in Russian)

Kuzmichev, V., Verstov, V. (2017a). Vibration activators in the construction production technology. Architecture and Engineering, 2 (1), pp. 24-32. DOI: 10.23968/2500-0055-2017-2-1-41-50

Kuzmichev, V., Verstov, V. (2017b). Vessel mixers with vibration activator in construction engineering. Architecture and Engineering, 2 (2). pp.20-26. DOI: 10.23968/2500-0055-2017-2-2-20-26

Verstov, V.V., Tishkin, D.D., Romanovsky, V.N. (2013). Sovershenstvovanie tekhnologii bespodkladochnogo montazha promyshlennogo oborudovaniia [Improvement of the technology of installation of industrial equipment without backing plates]. Installation and special works in construction, 7, pp. 27-31. (in Russian) 